\title{
The production of Titanium Powder via Hydrogen Reduction of Titanium Tetrachloride by Inductively Coupled RF plasma
}

\author{
Sung-hun Park ${ }^{\mathrm{a}}$, So-yeong Lee ${ }^{\mathrm{a}}$, Ho-seong Lee ${ }^{\mathrm{a}}$, Ho-sang Son ${ }^{\mathrm{a},{ }^{*}}$ \\ ${ }^{a}$ School of Materials Science and Engineering, Kyungpook National University, Daegu, Republic Of Korea \\ *sohn@knu.ac.kr
}

\begin{abstract}
$\underline{\text { Abstract }}$
In this study, the production of titanium powder via hydrogen reduction of titanium tetrachloride by inductively coupled radio frequency plasma was investigated. While titanium tetrachloride is hard to be reduced by hydrogen thermodynamically, dissociated hydrogen radical which formed from hydrogen gas passing through the plasma can react with titanium tetrachloride to form hydrochloric acid and subsequently produce titanium. The frequency of generator used in this experiment was $13.56 \mathrm{MHz}$ and input power was varied. The characteristics of the powder such as powder size, size distribution, and phases were analyzed with $\mathrm{x}$-ray diffractometer, field emission scanning electron microscope, energy dispersive x-ray spectrometer and transmission electron microscope. The deposited height of titanium powders, after 4 minutes reaction, were $4.004 \mu \mathrm{m}$ and loosely attached that could be easily collected. The morphology of powders was found to be more spherical with the increase in applied input power. Most of the powders were composed of titanium and oxygen. The average diameter of powders was approximately $200 \mathrm{~nm}$.
\end{abstract}

\section{Introduction}

Titanium is the ninth most abundant element, comprising $0.6 \%$ of the earth's crust. It is also the fourth most abundant structural material after aluminum (8.1 $\%)$, iron (5.1\%) and magnesium (2.1\%) [1]. However, a price of titanium is inversely the most expensive material among these four elements. The main reason for this is due to the high oxygen affinity of titanium which makes the process for producing metallic titanium from titanium ore complicated. Presently, while a high-grade titanium sponge can be produced by Kroll process (the conventional method of smelting titanium), it performs in the batch nature which needs high energy costs and has a low production yield [2]. Besides, many of the subsequent process steps required to produce titanium metal such as melt processing, mill processing and multiple conditioning steps that cause yield loss and cost of product much higher [1]. Accordingly, if a lot of process steps could be reduced, it would lower the cost of titanium products. Thus, there was a lot of attempts to develop process to produce ingot or powder directly from rutile $\left(\mathrm{TiO}_{2}\right)$ or titanium tetrachloride $\left(\mathrm{TiCl}_{4}\right)$. In particular, the production of metal powders by reducing ores using thermal plasma attracts great interest. Previously, several researchers had studied the feasibility of producing titanium powders from $\mathrm{TiCl}_{4}$ using plasma. Miller et al [3] proposed equilibrium calculations of Ar-Ti-Cl-H by solving equilibrium constant equations of $101.325 \mathrm{kPa}$ total pressure. It seems that no polyatomic species existed above $4,000 \mathrm{~K}$ and the experimental results show that $\mathrm{TiCl}_{4}$ was reduced to $\mathrm{TiCl}_{3}$ by $\mathrm{H}_{2}$ using $\mathrm{RF}$ plasma. Hutchison et al [4] examined $\mathrm{Ti}-\mathrm{Cl}-\mathrm{H}$ system in a $95 \%$ argon thermal plasma of $101.325 \mathrm{kPa}$ total pressure over 2,000-6,000 K using free energy minimization. The effect of using a methane gas when the contamination of oxygen occurred in the reduction of $\mathrm{TiCl}_{4}$ by hydrogen was also studied. Particularly, in order to avoid back reactions and recombination of produced titanium with that chloride, the rapid quenching of a plasma jet in argon, hydrogen and $\mathrm{TiCl}_{4}$ was suggested. Murphy [5] also reported the feasibility of the production of titanium nanoparticles in an atmospheric-pressure thermal plasma containing argon, hydrogen and $\mathrm{TiCl}_{4}$. The calculations of the chemical equilibrium composition of mixtures was considered with nucleation parameters, a quench rate, yield and mean particle size of titanium with various initial mixtures of argon, hydrogen and $\mathrm{TiCl}_{4}$. It was also noted that the reverse reaction could be occurred, resulting in the formation of titanium subchlorides, when the quenching rate is not sufficiently high. In the present study, in order to examine the feasibility of the production of titanium powder in a plasma, the inductively 
coupled radio frequency (R.F.) plasma has been used with hydrogen, argon and $\mathrm{TiCl}_{4}$. In order to form the rapid quenching by the plasma jet, the plasma torch was designed to make sheath flow stream swirling.

\section{Experimental}

\section{1. Experimental apparatus}

A schematic diagram of the experimental apparatus is shown in Fig. 1. The apparatus consisted of a RF generator, RF matching unit, plasma torch, reaction chamber, and evacuation system. The plasma torch was designed as double flux torch by locating two of quartz tubes (inner and outer confinement tube) concentrically to introduce two different gas streams (central gas flow stream and sheath gas flow stream) into the discharge region separately. The sheath gas flow stream was generated by supplying argon gas in tangential flow to make the stream swirling along the outer perimeter of the inner tube so that the tubes could be protected from thermal damage. A mixture of argon gas and hydrogen gas supplied in axial flow into the inner tube to generate the central gas flow stream which is directed toward the center of the discharge region. The injection probe was placed axially into the center of the confinement tube and its tip was protruded from the end of the inner tube to introduce precursor directly into the discharge region. The outer tube was surrounded by a 5 or 6 turn, watercooled, copper induction coil, which is connected to the RF matching box. A water-cooled coil was also applied to the bottom of the plasma torch body and every flange. Evacuated gases were passed through a filter and a scrubber by a vacuum pump and produced powders were collected in filter. Also, titanium rod and glass slide were placed in the reaction chamber to deposit the produced powders.

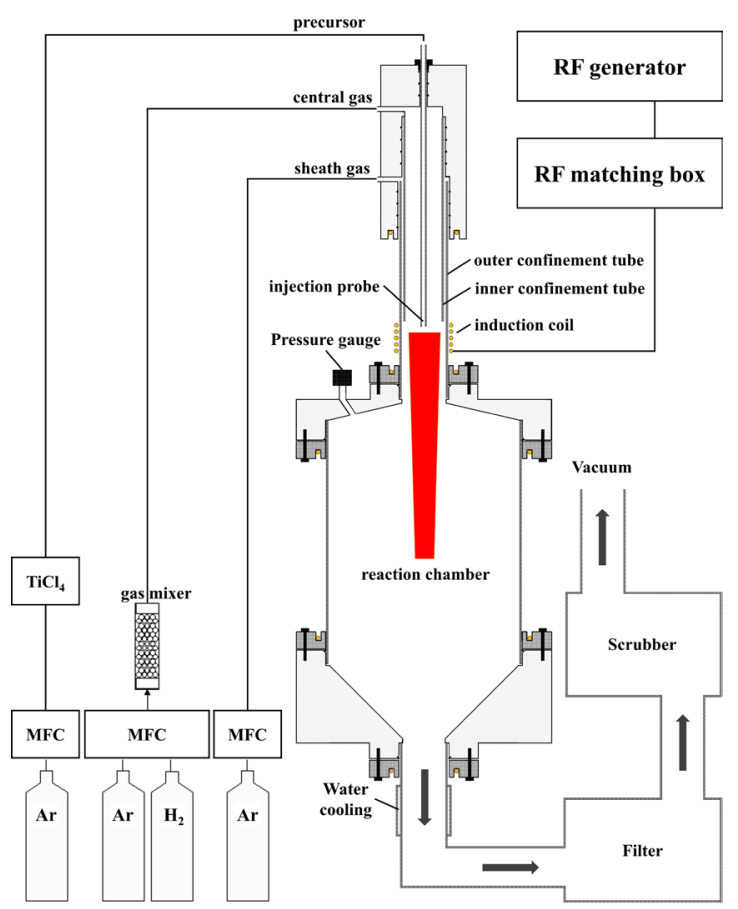

Fig. 1 Schematic representation of experimental setup for inductively coupled RF hydrogen plasma reduction of $\mathrm{TiCl}_{4}$. 


\section{2. Experimental procedure}

Firstly, the reaction chamber was purged by vacuum pump with supplying an argon gas to convert into an inert atmosphere. After that, the plasma torch was ran at a frequency of $13.56 \mathrm{MHz}$ with $0.5-1.0 \mathrm{~kW}$ input power and a flow rate of the supplied argon gas was varied to discharge an argon plasma. When the plasma was discharged and maintained, a hydrogen gas was introduced to convert an argon plasma into a hydrogen plasma. Subsequently, titanium tetrachloride ( $\mathrm{TiCl}_{4}, 99.9 \%$ purity, Aldrich Co.) was injected into the hydrogen plasma in liquid phase by an Ar-carrier gas. A feeding rate of $\mathrm{TiCl}_{4}$ was $0.1 \mathrm{~mL} / \mathrm{min}$ and a flow rate of Ar-carrier gas was $1 \mathrm{~L} / \mathrm{min}$. The detailed experimental conditions are given in Table 1. After the reaction, produced powders was collected from the filter, titanium rod and glass slide. To determine the phase compositions of produced powders, an X-ray diffractometer (Rigaku, D/Max-2500) was used. Also, the characteristics of the powders were analyzed using a FE-SEM/EDS (SU8220, Hitachi) and FE-TEM/EDS (Titan G2 ChemiSTEM, FEI Co.).

Table 1 Experimental conditions for $\mathrm{H}_{2}$ plasma reduction

\begin{tabular}{ll}
\hline Input power & $0.5-1.0 \mathrm{~kW}$ \\
RF frequency & $13.56 \mathrm{MHz}$ \\
$\mathrm{TiCl}_{4}$ feeding rate & $1 \mathrm{~mL} / \mathrm{min}($ Ar-carrier gas: $1 \mathrm{~L} / \mathrm{min})$ \\
$\mathrm{Ar}$ gas flow rate & Central flow stream: 0 or $2 \mathrm{~L} / \mathrm{min}$ \\
& Sheath flow steam: $1-15 \mathrm{~L} / \mathrm{min}$ \\
$\mathrm{H}_{2}$ gas flow rate & $0.1-1.0 \mathrm{~L} / \mathrm{min}$ \\
\hline
\end{tabular}

\section{Results and discussions}

When the $\mathrm{TiCl}_{4}$ was fed into the plasma torch, the plasma had flashed in an instant and becomes much brighter. An inspection of the apparatus after the experiment indicated that a reduction product had formed which deposited on the inner reaction chamber, titanium rod, glass slide and filter. All of the deposited powders were loosely attached and could be easily collected. Fig. 3 shows the X-ray diffraction pattern of the powder produced under the following conditions: $0.7 \mathrm{~kW}$ of input power; $0.1 \mathrm{~L} / \mathrm{min}$ of $\mathrm{H}_{2}$ gas; $2 \mathrm{~L} / \mathrm{min}$ of Ar-central gas; $15 \mathrm{~L} / \mathrm{min}$ of Ar-sheath gas; and 4 minutes of operating time. The XRD pattern of the powder shows a broad hump and no any sharp diffraction peaks that indicate an amorphous phase. Although there was no quenching system on the reaction chamber, it seems that the produced powder was quenched by a high sheath gas stream as soon as it escaped from plasma region.

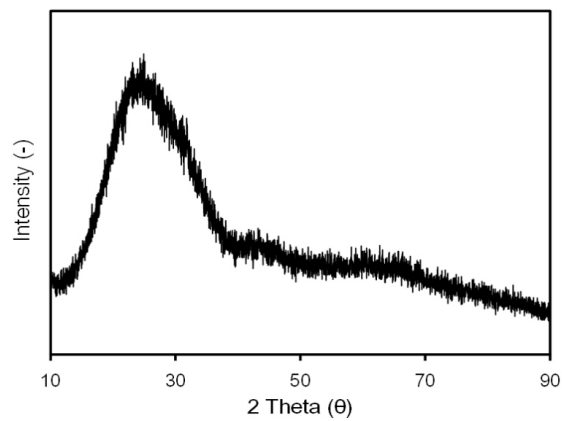

Fig. 2 X-Ray diffraction pattern of the powder produced under 4 min reaction at $0.7 \mathrm{~kW}$, Ar-sheath: $15 \mathrm{~L} / \mathrm{min}, \mathrm{Ar}-\mathrm{central}: 2 \mathrm{~L} / \mathrm{min}$ and $\mathrm{H}_{2}: 0.1 \mathrm{~L} / \mathrm{min}$. 
It could be more obviously confirmed by the result of TEM images as shown in Fig. 3. Fig. 3(b) shows the HRTEM image of the produced powder, which does not contain any fringe spacing, confirming the formation of an amorphous phase. Also, the SAED pattern which shown in Fig. 3(c) clearly shows the amorphous phase of the produced powder. It contains a halo ring pattern instead of diffraction rings in contrast with crystalline material. Though distinguishing each powder size is difficult because of the powder agglomeration, the mean particle diameter is estimated to be 100-200 nm. An energy dispersive X-ray spectroscopy (EDS) analysis was also conducted to determine the elements present in the produced powders. As shown in Table 2, titanium, oxygen and chlorine are found in the powder and the content of each of the elements is 39.6 at. \%, 59.4 at. \% and 1.0 at. \%. Considering the stoichiometric ratio of the elements, therefore, the produced powder is considered as $\mathrm{Ti}_{2} \mathrm{O}_{3}$.
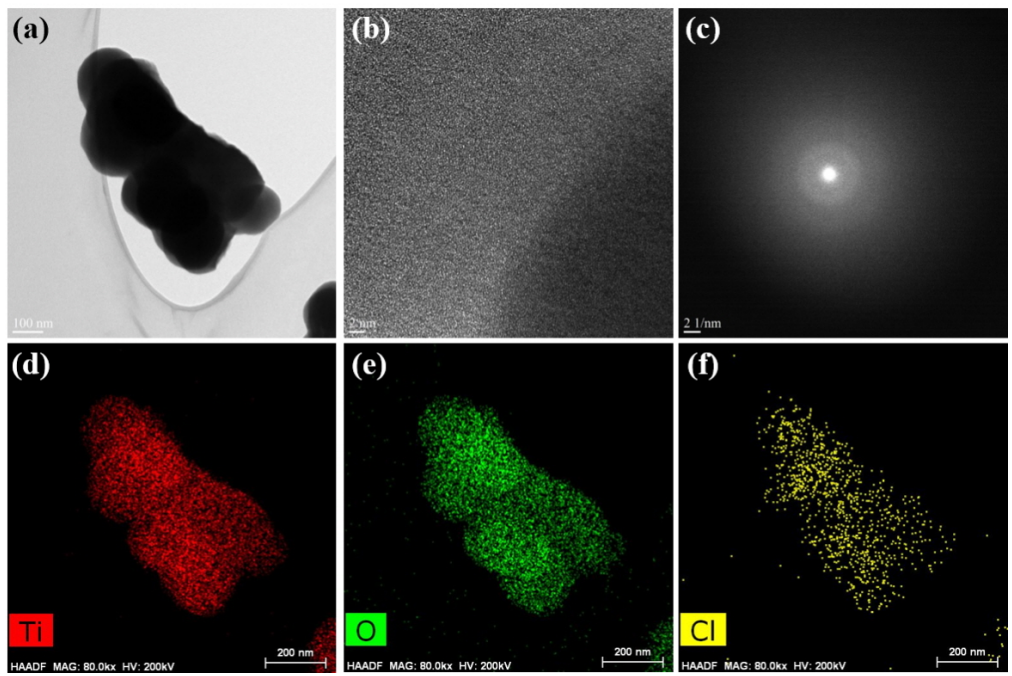

Fig. 3 TEM/EDS images of the powder produced under 4 min reaction at $0.7 \mathrm{~kW}$, Ar-sheath: $15 \mathrm{~L} / \mathrm{min}$, Ar-central: $2 \mathrm{~L} / \mathrm{min}$ and $\mathrm{H}_{2}: 0.1 \mathrm{~L} / \mathrm{min}$.

Table 2 The content of each of the elements presented in the Fig. 3.

\begin{tabular}{cccc}
\hline Element & $\mathrm{Ti}$ & $\mathrm{O}$ & $\mathrm{Cl}$ \\
\hline at. $\%$ & 39.6 & 59.4 & 1.0 \\
\hline
\end{tabular}

The height of the deposited powders on the titanium rod was measured by using focused ion beam (FIB) that can cross-section a sample and then take a picture via scanning electron microscope (SEM). The height is approximately $4 \mu \mathrm{m}$ and, hence, the deposition rate can be calculated as $1 \mu \mathrm{m} / \mathrm{min}$. 

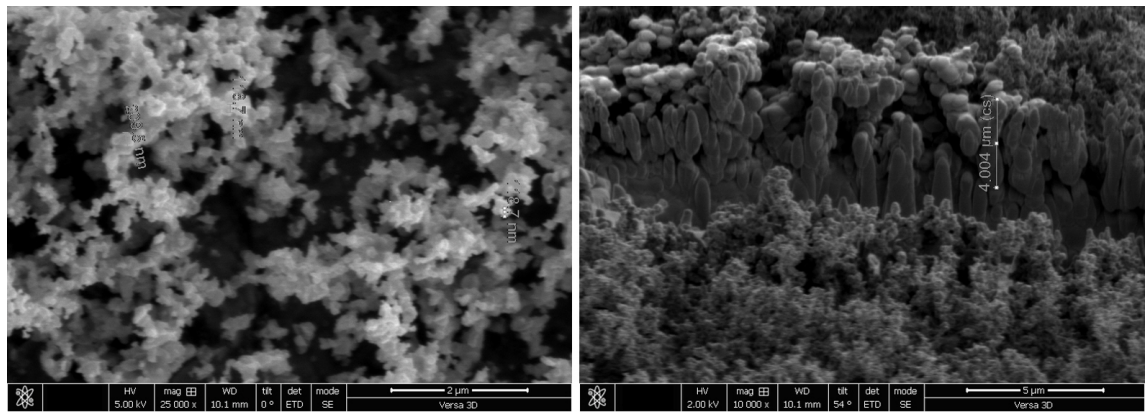

Fig. $4 \mathrm{FIB} / \mathrm{SEM}$ image of the powder deposited on the titanium rod under $4 \mathrm{~min}$ reaction at $0.7 \mathrm{~kW}$, Ar-sheath: $15 \mathrm{~L} / \mathrm{min}, \mathrm{Ar}$-central: $2 \mathrm{~L} / \mathrm{min}$ and $\mathrm{H} 2: 0.1 \mathrm{~L} / \mathrm{min}$.

Powder morphology was observed for various input power as shown in Fig. 5. The powders were produced under the following conditions: $0.5 \mathrm{~kW}$ of input power; $1 \mathrm{~L} / \mathrm{min}$ of $\mathrm{H}_{2}$ gas; $0 \mathrm{~L} / \mathrm{min}$ of Ar-central gas; $1 \mathrm{~L} / \mathrm{min}$ of Ar-sheath gas; and $1.0 \mathrm{~kW}$ of input power; $0.5 \mathrm{~L} / \mathrm{min}$ of $\mathrm{H}_{2}$ gas; $0 \mathrm{~L} / \mathrm{min}$ of Ar-central gas; 10 $\mathrm{L} / \mathrm{min}$ of Ar-sheath gas with 4 minutes of operating time. An increase in the input power from $0.5 \mathrm{~kW}$ to $1.0 \mathrm{~kW}$ results in the formation of powder with a more spherical shape. This may be due to the fact that the melting at the surface of powder occurs more easily at higher temperature caused by the increase in the input power. In addition, this causes the increase in the powder size. As shown in Fig. 5(b) and (e), the mean particle diameter is estimated to be 100-150 nm for the input power of $0.5 \mathrm{~kW}$ and $200-300 \mathrm{~nm}$ for the input power of $1.0 \mathrm{~kW}$. In order to identify the content of elements in these powder, EDS analysis was conducted and the results are shown in Fig. 5(c) and (f) and Table 3. The powder is composed mainly of titanium and oxygen, with a small amount of chlorine and silicon. The content of each of the elements in powder is 37.98 at. $\%[\mathrm{Ti}], 59.22$ at. $\%[\mathrm{O}], 2.48$ at.\%[Cl] and 0.32 at. $\%[\mathrm{Si}]$ at input power of $0.5 \mathrm{~kW}$ and 43.69 at.\%[Ti], 49.93 at.\%[O] and 6.37 at. $\%[\mathrm{Cl}]$ at input power of $1.0 \mathrm{~kW}$. From the stoichiometry, the powder produced at input power of $0.5 \mathrm{~kW}$ can be regarded as $\mathrm{Ti}_{2} \mathrm{O}_{3}$, which is in good agreement with the results in Fig. 3. However, it can be seen that the TiO powder is formed at input power of $1.0 \mathrm{~kW}$ (Table 3).
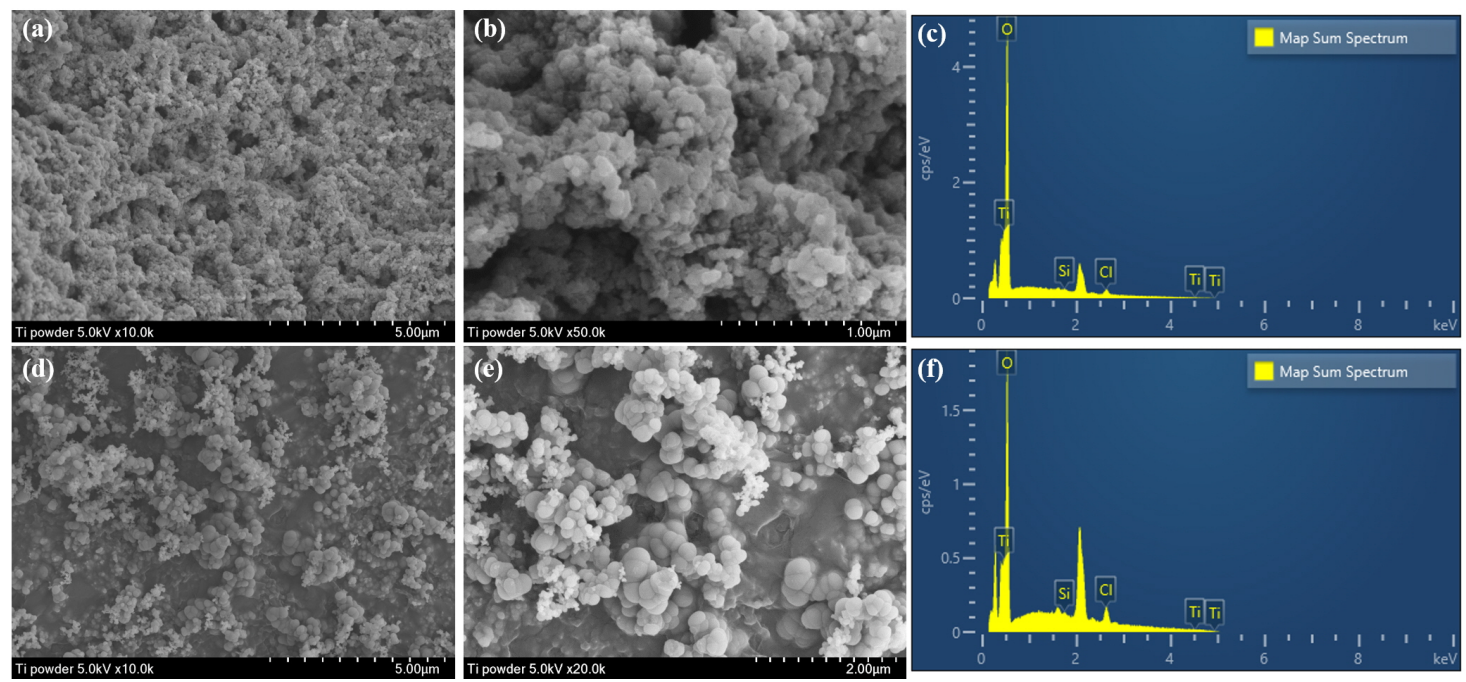
Fig. 5 FE-SEM images of the powder produced under 4 min reaction at (a), (b), (c): $0.5 \mathrm{~kW}$, Ar-sheath: $1 \mathrm{~L} / \mathrm{min}, \mathrm{Ar}-\mathrm{central:} 0 \mathrm{~L} / \mathrm{min}, \mathrm{H} 2: 1 \mathrm{~L} / \mathrm{min}$ and (d), (e), (f): 1.0 kW, Ar-sheath: $10 \mathrm{~L} / \mathrm{min}$, Ar-central: $0 \mathrm{~L} / \mathrm{min}, \mathrm{H}_{2}: 0.5 \mathrm{~L} / \mathrm{min}$.

Table 3 The content of each of the elements in powder produced at each input power.

\begin{tabular}{ccccc}
\hline \multirow{2}{*}{ Input power } & \multicolumn{5}{c}{ Elements (at. \%) } \\
\cline { 2 - 5 } & $\mathrm{Ti}$ & $\mathrm{O}$ & $\mathrm{Cl}$ & $\mathrm{Si}$ \\
\hline $0.5 \mathrm{~kW}$ & 37.98 & 59.22 & 2.48 & 0.32 \\
$1.0 \mathrm{~kW}$ & 43.69 & 49.93 & 6.37 & 0 \\
\hline
\end{tabular}

Although not illustrated in this literature, the produced powders collected on the filter showed a purple-colored and instantly turned gray-colored with releasing toxic gas during recovery. Therefore, we tried to identify the powder exactly, but as mentioned in the XRD analysis result in Fig. 2 , it was difficult to determine it. However, when considering the chemical species participating in the reaction, it seemed that the powder that appeared violet was $\mathrm{TiCl}_{3}$, which was inferred to be generated by the reverse reactions of titanium and titanium subchlorides due to insufficient quenching rate. Within the limits studied in this work, it will be confirmed through further experiments in the future.

\section{Conclusion}

The production of titanium powder via hydrogen reduction of titanium tetrachloride by inductively coupled RF plasma has been conducted. Most of the powders were composed of $\mathrm{Ti}$ and $\mathrm{O}$ and in stoichiometric the powders were produced as a $\mathrm{Ti}_{2} \mathrm{O}_{3}$ or $\mathrm{TiO}$ phase rather than pure titanium. The mean particle diameter was estimated to be $100-300 \mathrm{~nm}$ and the morphology of powders were found to be more spherical with the increase in applied RF input power. The deposited height of titanium powders, after 4 minutes reaction, were $4.004 \mu \mathrm{m}$ and loosely attached that could be easily collected.

\section{$\underline{\text { 5. References }}$}

[1] US Dept. of Energy / Oak Ridge National Laboratory, (2003) 1-55.

[2] H. S. Sohn and J. Y. Jung, J. of Korean Inst. of Resources Recycling 25(4) (2016) 68-79.

[3] R. C. Miller and R. J. Ayen, I\&EC Process Des. Deo. 8 (1969) 370-377.

[4] S. G. Hutchison, C. M. Wai, J. Dong and R. J. Kearney, Plasma Chem. Plasma Process. 15 (1995) 353-367.

[5] A. B. Murphy, J. Phys. D: Appl. Phys. 37 (2004) 2841-2847. 